$\mathbb{P}$ periodica polytechnica

Civil Engineering

$58 / 1(2014) 4753$

doi: $10.3311 / P P c i .7406$

http://periodicapolytechnica.org/ci

Creative Commons Attribution (1)

RESEARCH ARTICLE

\section{Travel Time Delay at Pedestrian Crossings Based on Microsimulations}

\author{
István Fi / Zsuzsanna Kovács Igazvölgyi
}

Received 2013-07-24, revised 2013-10-29, accepted 2013-12-11

\begin{abstract}
Analysis of pedestrians is always a current issue, there are frequent crowded trams, tram platforms and long waiting time at zebra crossings. The unsignalized pedestrian crossing analyses are very important because these crossings have a crucial role in transport planning. The accident data show decreasing tendency in the pedestrian accidents although the decrease is not too significant. The rate of the pedestrian accidents on zebra crossings is significant; from 2009 to 2012 this rate was on zebra crossings between 32-34\%. The VISSIM microsimulation analyses on unsignalised zebra crossings with and without refuge island. Based on the simulation results and international studies, these two facility types are compared. The article provides a recommendation for these facilities (zebra crossing with and without refuge island) for different vehicle volumes and for medium and high pedestrian volumes.
\end{abstract}

\section{Keywords}

pedestrian - zebra crossing with and without refuge island. accident data $\cdot$ delay $\cdot$ VISSIM $\cdot$ microsimulation running

\section{István $\mathbf{F i}$}

Department of Highway and Railway Engineering, Budapest University of Technology and Economics, Múegyetem rkp. 3, H-1111 Budapest, Hungary e-mail: fi@uvt.bme.hu

\section{Zsuzsanna Kovács Igazvölgyi}

Department of Highway and Railway Engineering, Budapest University of Technology and Economics, Múegyetem rkp. 3, H-1111 Budapest, Hungary e-mail: igazvolgyi@uvt.bme.hu

\section{Current issue}

The handling of transport problems are generally not in the focus in Hungary. This statement is specifically true for big cities of the former socialist countries, where the followings characteristics can be found. A dense and narrow ring-radial road network was generally built in these cities in the earlier century which does not properly replace the necessary urban highway elements of our recent times. The public transport parameters about twenty years ago represented a very good service level, but nowadays in the lack of investment sources operate slowly with crowding trams. The consequence of this circumstance is that local authorities do not take pedestrian problems into consideration. But the high pedestrian number of traffic accidents show that it is very important to pay attention to pedestrian movements and pedestrian areas. The pedestrian accident data from the last 10 years show decreasing tendency but the degree of decreasing in urban area is greater than in rural area. The drivers often do not give yield to pedestrians. In 2003 there was 1244 , in 2012 just 794 pedestrians injured in accidents. The rate of the pedestrian accidents on zebra crossings is significant; from 2009 to 2012 this rate was on zebra crossings between 32$34 \%$. Unfortunately this increasing tendency confirms the fact that it is very crucial to analyse the pedestrian movements and accidents on zebra crossings. Based on the 10 years data, $\mathrm{KSH}$, 2003-2012 [15]) the average severity of accident was created. (see Fig. 1). The average severity of accident can be calculated with the weighing factors (weighing factor are the following: 5 for slightly injured, 70 for serious, 130 for fatal accident), which shows that the accident in rural area is more serious than the urban area. The severity of pedestrian accidents was decreased in the analysed years (2003-2012), the accident severity in Budapest is fewer than the national value.

\section{National and international pedestrian analyses}

This paper aims to begin an analysis about most frequently conflict area of pedestrians and vehicle traffic. On the basis of pedestrian analysis, new pedestrian design standard can be made. The paper presents the results and international experience about unsignalized pedestrian crossings and the results 


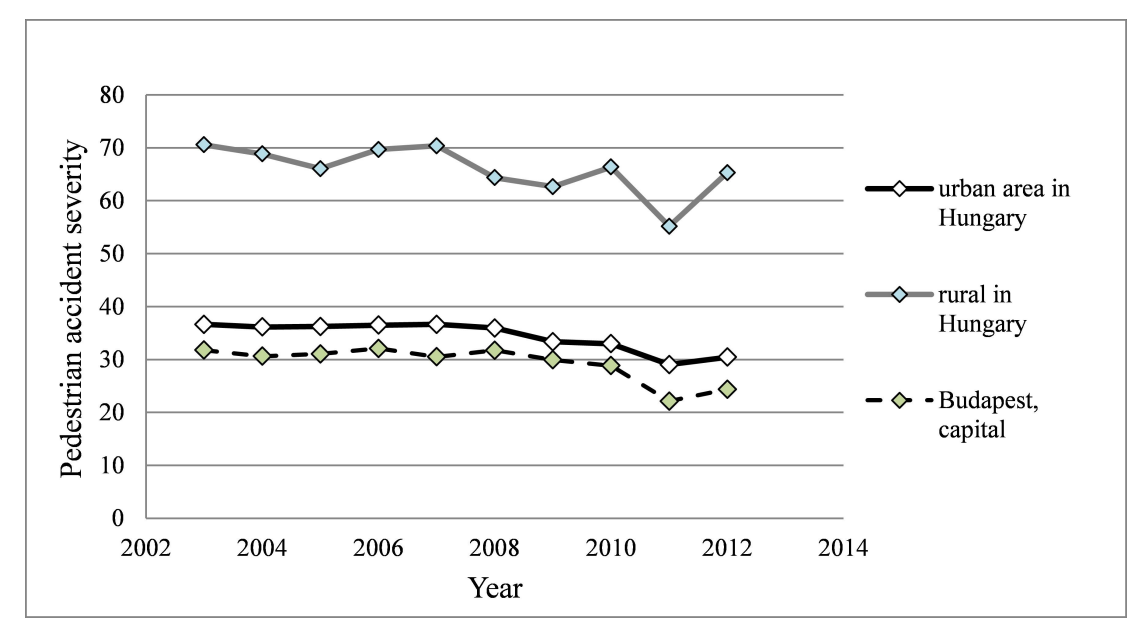

Fig. 1. Pedestrian accident's severity from 2003-2012 in Hungary and in Budapest (Source: KSH [15])

of the VISSIM simulations. The biggest advantage of the microsimulation software is that it gives more data for different volumes. The issue is up to date, because pedestrians are vulnerable transport participants. In modern times we are in a hurry and constantly speak on mobile phones. A study from Australia analysed "The effects of mobile phone use on pedestrian crossing behaviour at signalised and unsignalized intersections" (Hatfield, 2007 [7]). Talking on a mobile was associated with slower crossing speeds for females at signalised crossings, and for males at unsignalized crossings. The speed distributions can be set in the model. The Department of Highway and Railway Engineering analysed vehicle flow's relationships on road networks in the last 10 years. New capacity was recommended for Hungarian highways ( $\mathrm{Fi}$ and Galuska, 2010 [4]), travel time prediction by advanced neural network (Kisgyörgy and Rilett, 2002 [13]). Schuchmann measured the road network vulnerability (Schuchmann, 2010 [18]). In Hungary in 1980s two researchers analysed pedestrian movements. Some parameters of vehicles come from these studies.

János Berényi's C.Sc thesis (Berényi, 1989 [1]) analysed the main pedestrian flow's relationships. With his results steps and walkways for different level of service can be designed. The "metro handbook" and the "urban transport design handbook" use his recommendation. János Juhász made an own model for the pedestrian crossings for analysing the accident risks of crossings (Juhász, 1998 [11]). Juhász's PhD thesis (Juhász, 2007 [12]) presents his results with his SIMPAS model (Simulation de Passage Piéton - The Simulation of the pedestrian crossing) where he pointed out that the average waiting time increases when the vehicle flow volume increases. The lowest waiting time is at the crossing with refuge island. His results showed that the pedestrian waiting time depends on the pedestrian arrival distribution. The waiting time for the groups is lower. In the SIMPAS model, the drivers and pedestrians always follow the rules.

\section{Pedestrian delay and the level of service (LoS)}

Before the methods of the pedestrian delay it is important to describe some definitions. The Level of Service (following LoS) is a measure used by traffic engineers to determine the effectiveness of elements of transportation infrastructure. The Highway Capacity Manual using letters 'A' to ' $F$ ', with ' $A$ ' being the best and ' $F$ ' being the worst. The definition of the time delay is the following: "Additional travel time (recently second) experienced by a driver, passenger, cyclist, or pedestrian beyond that required to travel at desired speed" (HCM 2010 [9]). For evaluation of the pedestrian time delay there are two main methods. One of them comes from Virkler (assuming random vehicle arrivals and normal crossing speeds) in 1996 (FHWA, 1998 [5]) describes an equation for calculating pedestrian delay based on queening theory.

Smith et al (1987) refer to an earlier study that demonstrated the effect of crossing width and conflicting vehicle volume on pedestrian delay (FHWA, 1998 [5]). The main difference is between the two methods are the number of lanes. Smith used his methods for different number of lanes, for example 2, 3, 4 and 5. Based on the methods the planner can determinate the calculated average pedestrian delay for different vehicle volumes [comparing the different method and the results of the article are in the conclusion]. These results are compared with the results of this article. The biggest difference is that the microsimulation was run with different pedestrian flow.

The pedestrian delay depends on the vehicle and pedestrian volume. On unsignalized zebra crossings, the pedestrian always has the right of way in Hungary based on Highway Code (Highway Code, $1975[10]$ ). A general problem is that vehicle drivers do not yield to pedestrians at unsignalized zebra crossings. In the 'Save our Life' European Union project (2012 [17]) the researchers of Institute for Transport Sciences Non Profit Ltd (KTI) carried out a study in 2011. They analysed the situations, which were classified in 5 big categories. The results show that just 55-60\% percent of drivers give yield to pedestrians if the pedestrians want to cross. The different facility types have different rates of yielding (zebra, refuge island and roundabout) in 
Tab. 1. Different level of service at signalized and unsignalized intersection based on pedestrian delay (s) (HCM 2010 [9])

\begin{tabular}{|c|c|c|c|c|c|}
\hline \multicolumn{3}{|c|}{ Signalized } & \multicolumn{3}{|c|}{ Un-signalized } \\
\hline LOS & $\begin{array}{c}\text { Pedestrian delay }(\mathrm{s} / \mathrm{p}) \\
\text { (average) }\end{array}$ & Description & $\begin{array}{c}\text { Pedestrian delay }(\mathbf{s} / \mathbf{p}) \\
\text { (average) }\end{array}$ & Description & $\begin{array}{c}\text { Vehicle delay (s/pc) } \\
\text { (average) }\end{array}$ \\
\hline A & $<10$ & $\begin{array}{l}\text { very small delay, none } \\
\text { crossing irregularly }\end{array}$ & $<5$ & low & $0-10$ \\
\hline B & $10-20$ & $\begin{array}{l}\text { small delay, almost no one } \\
\text { crossing irregularly }\end{array}$ & $5-10$ & & $10-15$ \\
\hline C & $20-30$ & $\begin{array}{c}\text { small delay, very few } \\
\text { pedestrian crossing } \\
\text { irregularly }\end{array}$ & $10-20$ & moderate & $15-25$ \\
\hline D & $30-40$ & $\begin{array}{l}\text { big delay, someone start } \\
\text { crossing irregularly }\end{array}$ & $20-30$ & & $25-35$ \\
\hline E & $40-60$ & $\begin{array}{l}\text { very big delay, many } \\
\text { pedestrians crossing } \\
\text { irregularly }\end{array}$ & $30-45$ & high & $35-50$ \\
\hline $\mathbf{F}$ & $>60$ & $\begin{array}{l}\text { very big delay, almost every } \\
\text { waiting pedestrian crossing } \\
\text { irregularly }\end{array}$ & $>45$ & very high & $>50$ \\
\hline
\end{tabular}

the study, so the $50 \%$ rate was set in the simulation for the sake of safety.

The Highway Capacity Manual 2010 (HCM 2010 [9]) gives LoS criteria for different pedestrian facilities. The basis of the pedestrian LoS the density $(\mathrm{P} / \mathrm{m} 2)$, space $(\mathrm{m} 2 / \mathrm{P})$ and the average speed $(\mathrm{m} / \mathrm{s})$. The LoS categories of waiting, standing and the moving pedestrian are different. The Manual gives the LoS categories for signalized and un-signalized intersection too in the Table 1 for the whole crossing; at signalized intersection the delays can be higher for pedestrians. At LoS category ' $\mathrm{C}$ ' there is 20-30 s delay, which is small delay, but very few is the numbers of the jaywalkers.

The paper shows the delay method at zebra crossings, the Level of Services, and based on the measurement and international data (HCM, 2010 [9]) the microsimulation model is presented.

\section{VISSIM simulation models, inputs and the measure- ment}

The scenarios were set up in the Planung Transport Verkehr AG (PTV) VISSIM microsimulation software (PTV Vision, 2009 [16]). The VISSIM is an acronym for German words 'Verkehr in Städten - Simulation' which loosely translates to English as 'Traffic in towns simulations'. With this software of PTV Group the designer can simulate conflicts, test and design signalized, un-signalized intersections, public transport facilities and pedestrian crossings too. In the program the movement of pedestrians is based on the Social Force Model. "The basic idea is to model the elementary impetus for motion with forces analogously to Newtonian mechanics. From the social, psychological, and physical forces a total force results, which then sums up to the entirely physical parameter acceleration. The forces which influence a pedestrian's motion are caused by his intention to reach his destination as well as by other pedestrians and obstacles" (Helbing and Molnár, 1995 [8]). Thereby other pedestrians can have both an attractive and a repulsive influence.

In the scenarios, pedestrian crossings on two-way lanes roads in an urban area were analysed as unsignalized intersection with $v_{85 \%} 50 \mathrm{~km} / \mathrm{h}$ vehicle speed (urban area). The vehicle composition is homogeny, in VISSIM simulations there are just passenger cars. The vehicle lane is $3.5 \mathrm{~m}$, the pedestrian link is $3 \mathrm{~m}$ width. The pedestrian links connect in this models the two area, the area where are the start and the destination (input pedestrian demand). Just pedestrian can use these elements. The links of the vehicles are straight, it is important to know that there are no other nodes, junction on these. Lot of parameter can be set in the simulation, on them is the speed distribution. The applied pedestrian speed distribution comes from Weidmann and Schopf; where the mean pedestrian walking speed is $1.45 \mathrm{~m} / \mathrm{s}$ (Weidmann, 1993 [21]). The vehicle speed distribution comes from Berta (Berta, 2005 [2]) article, in which the effectiveness of the different traffic engineering tools were analysed. They measured vehicle speeds at unsignalized zebra crossing in Balatonfüred urban area on two ways roads. The minimum speed was $27 \mathrm{~km} / \mathrm{h}$, the maximum was $65 \mathrm{~km} / \mathrm{h}$. The two speed distributions were set in the VISSIM. In the VISSIM, new vehicle and pedestrian types were created to set new composition.

In the VISSIM there are two right of way definitions. In an earlier article 'conflict area' was used for one way roads (Igazvölgyi, 2013) [14], (Bönisch and Kretz 2009 [3]). In these simulations, the 'priority rule' was used; with the "conflict area" method can simulate just clear yielding. But the priority rule consists of one stop line (red) and one or more conflict markers (green bar) that are associated with the stop line. Depending on the current conditions at the conflict marker(s) the stop line allows vehicles/pedestrians to cross or not. As a rule of thumb, for free flow traffic on the main road the min. gap time is the relevant condition. [The definitions are the following: pedes- 
trian critical gap $=$ the minimum time during which a single pedestrian will not attempt to cross an intersection, expressed in seconds, gap = the time, in seconds, for the front bumper of the second of two successive vehicles to reach the starting point of the front bumper of the first.]. 100\% yield of pedestrian or vehicle can be simulated with the conflict area. The yielding percent is $50 \%$ in this article (based on earlier study). In the simulations the $50 \%$ percent of the pedestrians have a right of way at the crossings. That is the reason why two vehicle types were used: those who give and those who do not give the yield. If the pedestrians do not have the right of way, they can cross the street if the critical gap is enough. If the available gap is greater than the critical gap, pedestrian will cross if the gap is less than the critical gap, they will not cross, they have delay. During these simulations the average and maximum pedestrian and vehicle delay were measured. The priority rule was set based on the critical gap time, for 2 lanes the vehicle has to have $6.5 \mathrm{~s}$, pedestrian $9.0 \mathrm{~s}$ gap time (HCM, 2010 [9]). The models are the following: zebra crossing with and without refuge island (see Fig. 2), so the conflict areas are different. At the refuge island (see Fig. 3) the conflict area is shorter, the pedestrians cross the roads in two phases; they give or have a right of way always only for/from one vehicle flow. The refuge island, sometimes called middle island and refuge island is 2 meters wide in the model. The crossing time depends from the crossing's width and the walking speed. The analysed crossings are $3 \mathrm{~m}$ wide, the width of the lanes are $3.5 \mathrm{~m}$. The zebra crossing's (without refuge island) length is 7 meters. Nothing influenced the sight distance, although in the real life there are lot of parking cars near the crossings, traffic signs and trees. The size of the refuge island is the next: $3 \mathrm{~m}$ wide and $2 \mathrm{~m}$ long. The simulations were run with different pedestrian $(200$ and $600 \mathrm{P} / \mathrm{hr})$ and vehicle volumes (from $50 \mathrm{pc} / \mathrm{hr}$ to $1600 \mathrm{pc} / \mathrm{hr}$ ). The results are presents in the next chapter. The delays of the crossings were measured with measurement areas, which were 1.5-1.5 m longer than the sign of the zebra crossing.

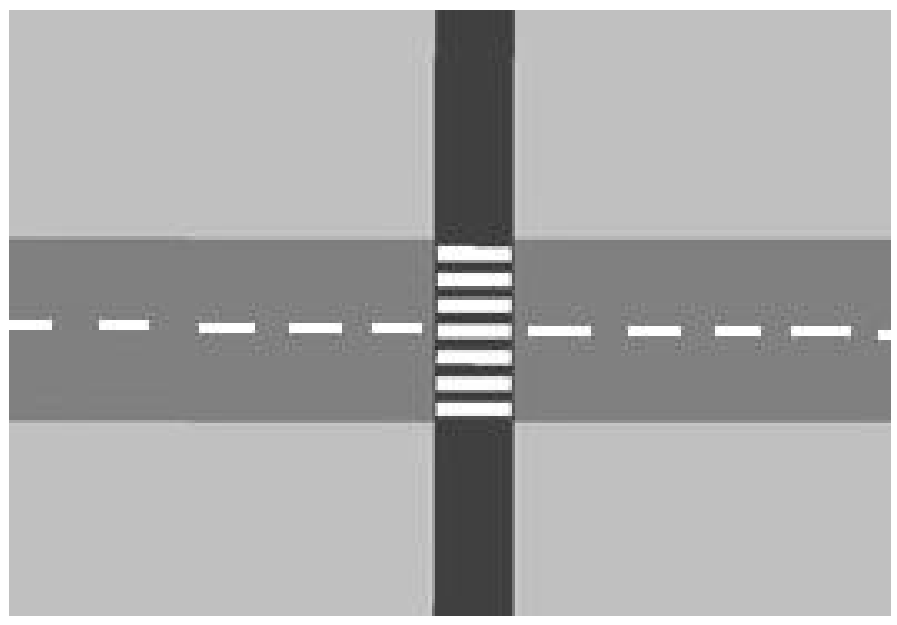

Fig. 2. Zebra crossing without refuge island

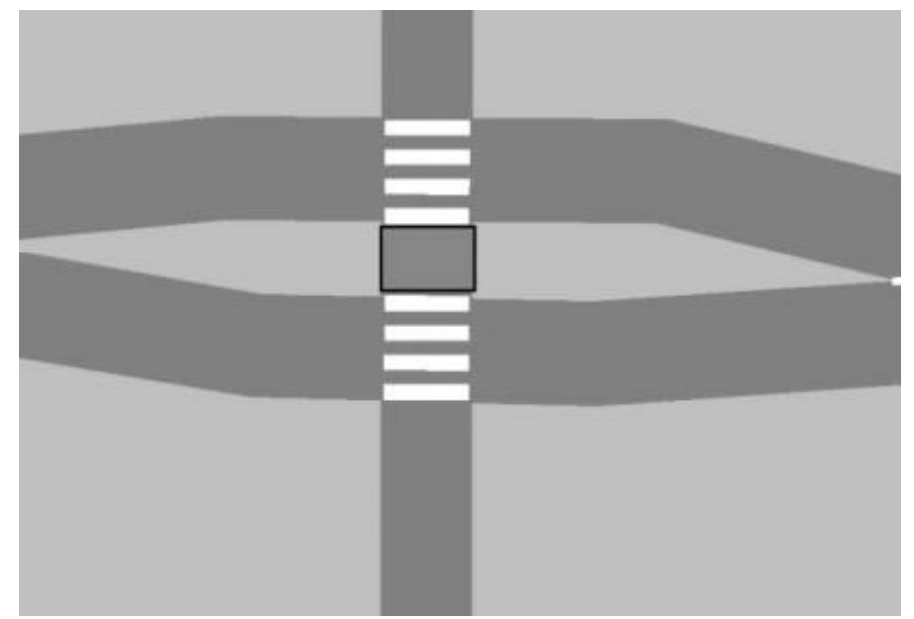

Fig. 3. Zebra crossing with refuge island

\section{Simulation results for zebra crossings with and with- out middle island}

The simulation running were run with 2 pedestrian volumes: 200 and $600 \mathrm{P} / \mathrm{hr}$ both directions. The Fig. 4 presents the crossings with and without refuge island. The figure shows the effects for the average vehicle delays; the crossing is seen as an unsignalized crossing and can be calculated as a TWSC (HCM, 2010 [9]). The average vehicle delay are under 15 seconds at the middle island facility. The vehicle delay increases with the vehicle volume exponential; the correlation is high $\mathrm{R}^{2}$ is over 0.9. With the increasing of the pedestrian volume the vehicles delay increase too. At zebra crossing with $600 \mathrm{P} / \mathrm{hr}$ pedestrian flow there was no "error message" until $1300 \mathrm{pc} / \mathrm{hr}$ vehicle volume. Without refuge island the $\mathrm{LoS}$ of vehicles is $\mathrm{C}$ from $1000 \mathrm{pc} / \mathrm{hr}$, with refuge island from $1400 \mathrm{pc} / \mathrm{hr}$ the vehicles reach the LoS C. With smaller (200P/hr) pedestrian volume the LoS is better. During the simulations the LoS did not reach LoS D (until $1600 \mathrm{pc} / \mathrm{hr}$ ). The Figure 4 shows the advantages of the refuge island. ( $1600 \mathrm{pc} / \mathrm{hr}$ volume was set as the highest volume in the simulations) The 25 seconds time delay is ' $\mathrm{D}$ ' Level of Service for vehicles. Till $600 \mathrm{P} / \mathrm{hr}$ pedestrian volume and under $1100 \mathrm{pc} / \mathrm{hr}$ vehicle volume the zebra crossing operate well without refuge island. Between 1100 and $1600 \mathrm{pc} / \mathrm{hr}$ can use zebra crossings with refuge island. With $200 \mathrm{P} / \mathrm{hr}$ pedestrian volume a refuge island is not needed. Before the zebra crossings a travel time section (100 m long) was set in the VISSIM on vehicle links. On the section the program the average stop number of the vehicles measured. At zebra crossing without refuge island the number of stops vehicles are two more less than at zebra crossings with middle island. The Hungarian (ÚT 2-1.211, 2009 [20]) and the German standards (HBS, 2001 [6]) recommend for these volumes a traffic light. In the further research a traffic light will be simulated for these volume combinations; we do not have to forget that the traffic light generate unjustified stops for vehicle too. These stops and starts have environmental consequence (noise- and air pollution).

During the running the pedestrian delays were measured too. The average pedestrian delays increase exponentially with the 


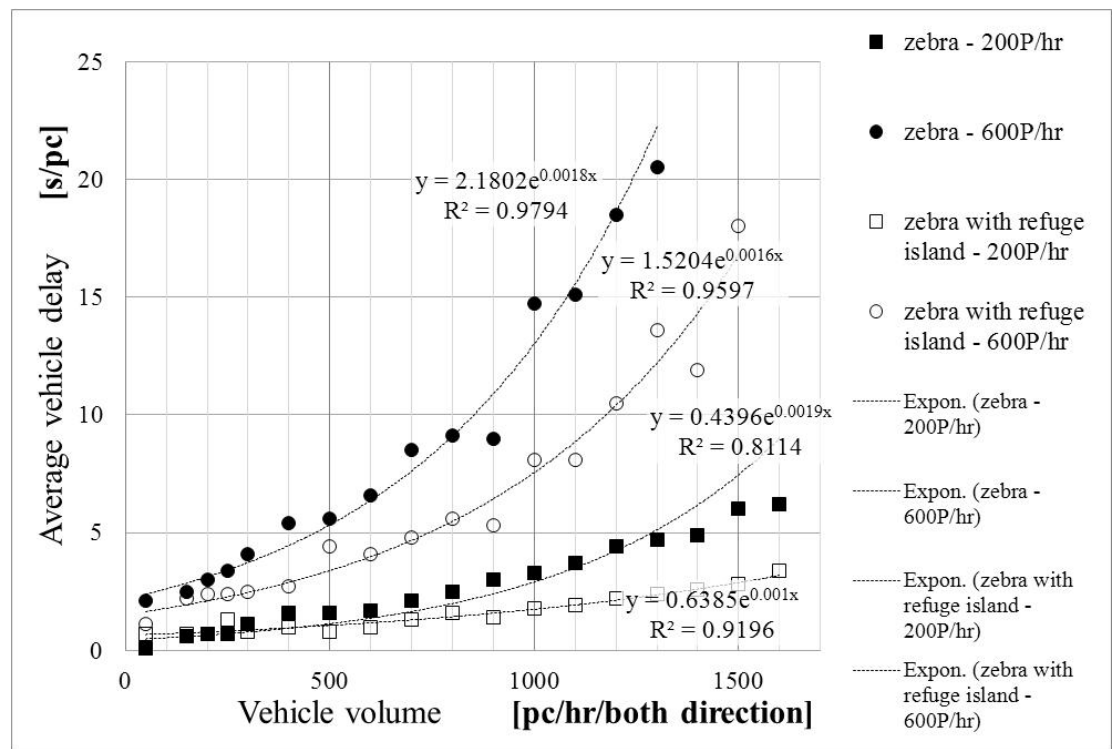

Fig. 4. Average vehicle delay at unsignalized zebra crossing with and without refuge island

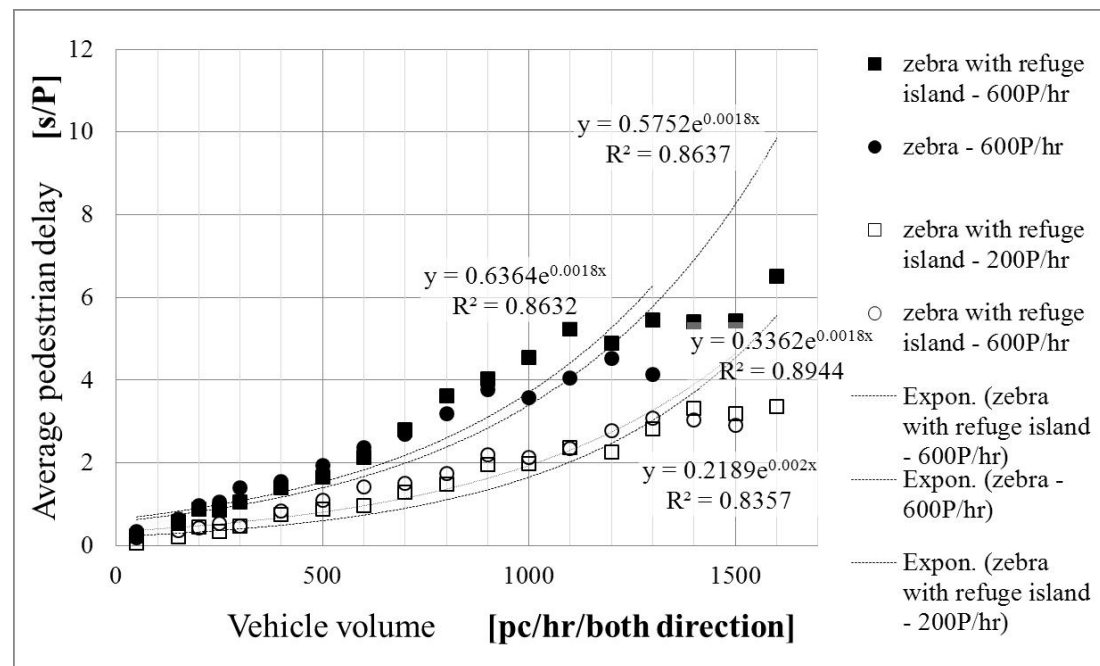

Fig. 5. Average pedestrian delay at unsignalized zebra crossing with and without refuge island

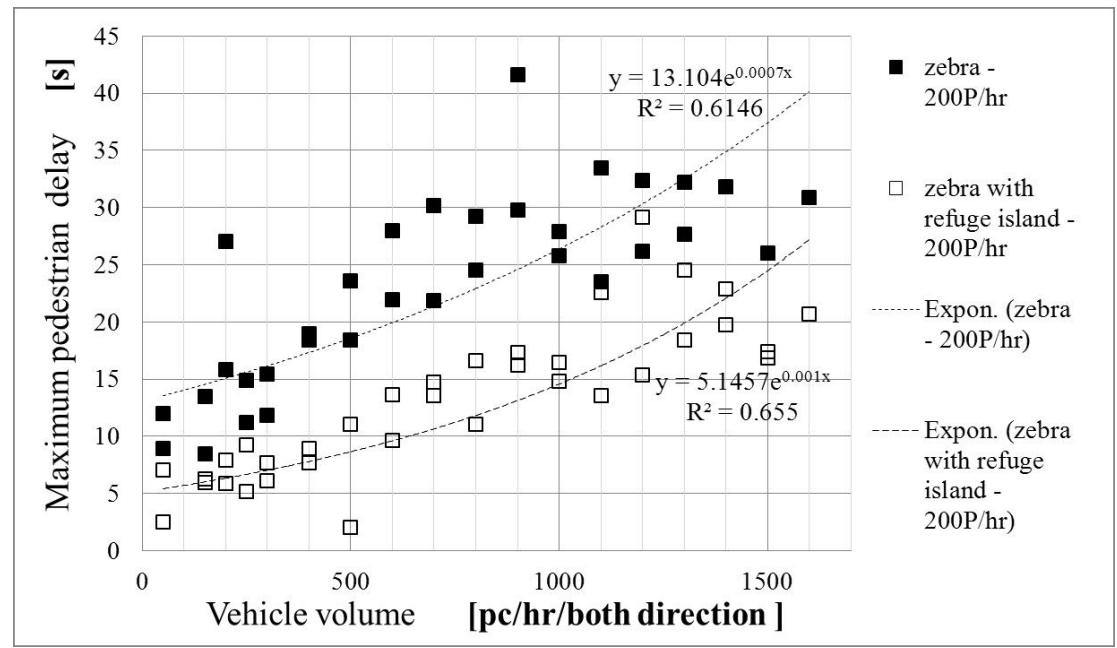

Fig. 6. Maximum pedestrian delay at unsignalized zebra crossing with and without refuge island 


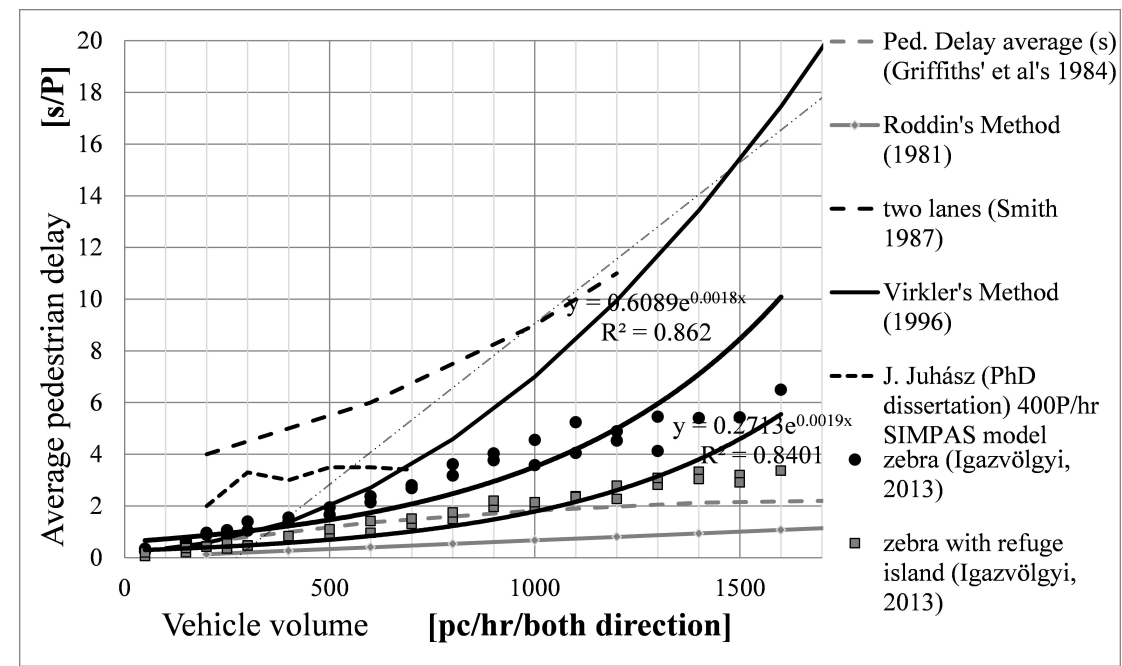

Fig. 7. Average pedestrian delay- comparing with different methods

vehicle volume too, like the vehicle delay (see Fig. 5). The correlations are high, over 0.8 . At middle island the average pedestrian delay is between $0.1 \mathrm{~s}$ and $4 \mathrm{~s}$, which is ' $\mathrm{A}$ ' Level of Service. At zebra crossing the LoS is over B (but under C) of the pedestrians over $1000 \mathrm{pc} / \mathrm{hr}$ vehicle volume. This is the other advantage of the refuge island. At $600 \mathrm{P} / \mathrm{hr}$ pedestrian volume the crossings delays are presented on Fig.5 for refuge island and without middle island. The different of the time delay are shown on the figure well. Till $500 \mathrm{pc} / \mathrm{hr}$ vehicle volume the advantage of the middle island is not too significant.

The maximum delay (Fig. 6) shows that till $400 \mathrm{pc} / \mathrm{hr}$ vehicle volume the differences are not too huge at zebra crossings with and without refuge island. After $400 \mathrm{pc} / \mathrm{hr}$ vehicle volume the maximum delay are more higher; at $1000 \mathrm{pc} / \mathrm{hr}$ it is between 15 and 28 second. The middle island has a positive effect for the maximum pedestrian delay too.

Pedestrian delay distribution was made from $600 \mathrm{P} / \mathrm{hr}$ pedestrian and $1500 \mathrm{pc} / \mathrm{hr}$ vehicle volume's simulation, which shows that the refuge island causes smaller average time delay; that maximum delay was 30 seconds. At zebra without refuge island the pedestrian delay was sometimes higher than 42 seconds.

\section{Conclusions and recommendation}

The PTV VISSIM simulation software can help in the planning. In the program the planner can set more vehicle and pedestrian types, for example elderly, children, regular and irregular pedestrian. The average waiting time can be measured in real life too, but the microsimulation software helps to analyse the situations for different volume combination and parameter settings. The refuge island has a positive effect for the pedestrian and for the vehicles too. The average pedestrian delays from the simulations are compared with other methods from transport methods and transport analyses. Smith and Juhász shortly described the average pedestrian delay in the 3.Pedestrian delay and the level of service (LoS). The exponential trends are the same as in Smith and Virkler studies. From $800 \mathrm{pc} / \mathrm{hr}$ the average pedestrian delay's difference from the Virkler Method is smaller, the Figure 7 shows the relationships. The simulations running confirmed international measurements and analyses. The time delay increases exponentially with the vehicle volume in every method.

The delays are smaller and give better Level of Service (LoS) with refuge island. Based on this analysis the traffic light is not necessary for $600 \mathrm{P} / \mathrm{hr}$ pedestrian volume in urban area, if the average vehicle speed is $50 \mathrm{~km} / \mathrm{h}$. Till $600 \mathrm{P} / \mathrm{hr}$ pedestrian volume and under $1200 \mathrm{pc} / \mathrm{hr}$ vehicle volume the zebra crossing is enough without refuge island, if the vehicle flow is homogeny and the average speed is $50 \mathrm{~km} / \mathrm{h}$. Between 1100 and $1600 \mathrm{pc} / \mathrm{hr}$ $(1600 \mathrm{pc} / \mathrm{hr}$ volume was set as the highest volume in the simulations) can use zebra crossings with refuge island. In the further research zebra crossings with traffic light will be analysed.

\section{Acknowledgements}

The work reported in the paper has been developed in the framework of the project "Talent care and cultivation in the scientific workshops of BME" project. This project is supported by the grant TÁMOP-4.2.2.B-10/1-2010-0009.

\section{References}

1 Berényi J, Pedestrian flow modelling for design transport facilities, C.Sc. Thesis, Budapest University of Technology and Economics; Budapest, 1989. language: Hungarian.

2 Berta T, Efficient safety increase of pedestrian crossings with traffic engineering means considering the risk factors, Városi közlekedés, $\mathbf{X L V ( 5 )}$ (2005), 296-303. language: Hungarian.

3 Bönisch C, Kretz T, Simulation of pedestrian crossing a street, 22-24 June 2009, preprintarXiv:0911.2902 poster session presented at: The Eighth International Conference on Traffic and Granular Flow'09, 8th Annual Conference TGF'09, Shanghai, China.

4 Fi I, Galuska J, Traffic analysis of two-lane highways, Periodica Polytechnica Civil Engineering, 55(2), (2011), 169-176, DOI 10.3311/pp.ci.20112.09

5 Rouphail N, Hummer J, Milazzo IIJ, Allen P, Capacity analysis of pedestrian and bicycle facilities, Federal Highway Administration U.S. Department of Transportation; North Carolina, 1998. 
6 Komission, Forschungsgesellschaft für Straßen- und Verkehrswesen, In: Handbuch für die Bemessung von Strassenverkehrsanlagen, FGSV-Verlag, 2001, pp. 1-37. language: German.

7 Hatfield J, Murphy S, The effects of mobile phone use on pedestrian crossing behaviour at signalized and unsignalized intersection, Sydney Accident Analyses and Prevention, 39, (2007), 197-205, DOI 10.1016/j.aap.2007.04.005

8 Helbing D, Molnár P, Social force model for pedestrian dynamics, Institute of Theoretical Physics, 51, (1995), 4282-4286, DOI 10.1103/PhysRevE.51.4282

9 National Research Council, Highway Capacity Manual, Transport research board (TRB); United States of America, 2010. ISBN 978-0-30916077-3.

10 KPM-BM decree, Highway Code, 1975, http://net.jogtar.hu/jr/ gen/hjegy_doc.cgi?docid=97500001.KPM language: Hungarian.

11 Juhász J, SIMPAS: A model of the flow of traffic at pedestrian crossings, Periodica Polytechnica Transport Engineering, 26(1-2), (1998), 131-146.

12 Juhász $\mathbf{J}$, The examination of road traffic flow and accident risk of pedestrian crossing in the surroundings of zebra crossings, $\mathrm{PhD}$ thesis, Faculty of Transportation Engineering, Budapest University of Technology and Economics; Budapest, Hungary, 2007.

13 Kisgyörgy L, Rilett LR, Travel time prediction by advanced neural network, Periodica Polytechnica Civil Engineering, 46(1), (2002), 15-32.

14 Kovács Igazvölgyi Z, Analyses of pedestrian characteristics at zebra crossings on one way road, Pollack Periodica, 8(2), (2013), 67-76, DOI 10.1556/Pollack.8.2013.2.8

15 Hungarian Central Statistical Office, Traffic Accidents, 2001-2012.

16 VISSIM 5.20 User Manual, PTV Group; Karlsruhe, Germany, 2009.

17 Save our life, 2012, http://www.sol-project.eu European Programme of Territorial Cooperation.

18 Schuchmann G, Road network vulnerability-evaluation of measures in ranking damages and developments, Periodica Polytechnica Civil Engineering, 54(1), (2010), 61-65, DOI 10.3311/pp.ci.2010-1.07

19 Transportation Research Board, Improving pedestrian safety at unsignalized crossings, 2006. TCRP Report 112.

20 Magyar Útügyi Társaság, Design of public road facilities for pedestrian traffic, 2006. language: Hungarian.

21 Wiedmann U, Transporttechnik der Fussgänger, IVT, Institut für Verkehrsplanung, Transporttechnik, Strassen- und Eisenbahnbau; Zürich, 1993, DOI 10.3929/ethz-a-000687810 http://ecollection.library.ethz.ch/eserv/eth:5929/eth-5929-01.pdf. 